\title{
Uludere-Uzungeçit (Şırnak) yöresinde (Güneydoğu Anadolu Otoktonu Doğu Bölümü) Alt Triyas Yaşlı Çığlı Grubu Kayaçlarının Diyajenez/Metamorfizma Tarihçesi
}

\author{
Diagenesis/Metamorphism History of Lower Triassic Çı̆̆ll Group Rocks in Uludere-Uzungeçit \\ (Sirnak) area (Eastern Part of the Southeast Anatolian Autochthone)
}

Sema TETIKER ${ }^{1}$, Hüseyin YALÇIN ${ }^{2}$, Ömer BOZKAYA ${ }^{3}$

${ }^{1}$ Batman Üniversitesi, Jeoloji Mühendisliği Bölümü, 72100 Batman

${ }^{2}$ Cumhuriyet Üniversitesi, Jeoloji Mühendisliği Bölümü, 58140 Sivas

${ }^{3}$ Pamukkale Üniversitesi, Jeoloji Mühendisliği Bölümü, 20070 Denizli

(sema.tetiker@batman.edu.tr)

\section{Öz}

Bu çalışmada, Güneydoğu Anadolu Otoktonu'nun (GDAO) Uludere-Uzungeçit (Şırnak) bölgesinde Çığlı Grubu'na ait karbonat ve pelitik kayaçların mineralojik özelliklerinin ortaya konulması amaçlanmıştır. Çığlı Grubu, alttan üste doğru Yoncalı Formasyonu (kireçtaşı arakatkılı dolomit-silttaşı-şeyl); Uludere Formasyonu (dolomit arakatkılı şeyl/karbonatlı şeyl-killi kireçtaşı) ve Uzungeçit Formasyonu (çört yumrulu kireçtaş1-dolomitik kireçtaş1-şeyl) ile temsil edilmektedir. XRD incelemeleri ile elde edilen minerallerin bolluk sırasına göre; Yoncalı Formasyonu karbonat (kalsit, dolomit), silis (kuvars, moganit), feldispat, fillosilikat (illit, klorit) ve götit; Uludere Formasyonu karbonat (kalsit, dolomit), kuvars, feldispat, fillosilikat (illit, klorit, karışık tabakalı klorit-vermikülit/C-V, sadece bir örnekte çok az miktarda kaolinit) ve hematit; Uzungeçit Formasyonu ise karbonat (dolomit, kalsit), silis (kuvars, opalCT, moganit), fillosilikat (klorit, illit), feldispat ve hematit içermektedir. İllit Kübler İndeksi-KI ( $\left.\Delta^{\circ} 2 \Theta\right)$ değerlerine göre; Yoncalı Formasyonu ankizon; Uludere ve Uzungeçit formasyonları ise ankizon-yüksek diyajenez derecesini yansıtmaktadır. Klorit Arkai İndeksi (AI, $\left.\Delta^{\circ} 2 \Theta\right)$ değerleri benzer biçimde ankizondiyajenez derecelerini işaret etmektedir. İllitler $2 M_{1}$ ve $2 M_{1}+1 M+1 M_{\mathrm{d}}$ politipleri sergilemekte olup, $b$ birim-hücre mesafesi değerleri ideal muskovite yakın bir bileşimi ve düşük basınç fasiyesi koşullarını göstermektedir. Çığlı Grubu kayaçları Diyarbakır-Hazro yöresindeki eşdeğer birimlere göre; kaolinitin ender bulunuşu, moganit ve C-V'in ortaya çıkışı ve çoğu seviyelerde dolomit ve hematitin baskınlığı, ayrıca diyajenez/metamorfizma derecelerinin yüksek olması bakımından farklılık sunmaktadır. Bu durum, Alt Triyas serilerinin bölgesel olarak Diyarbakır-Şırnak yönünde batıdan doğuya doğru daha derin bir çökelme ortamını yansıttığını, volkanik beslenim ve tektonik gömülmeyle daha yüksek olgunlaşma derecesine sahip olduğunu göstermektedir.

Anahtar Kelimeler: Arap Plakas1, XRD, Fillosilikat, $b$ birim-hücre mesafesi, Kristalinite 


\section{ABSTRACT}

This study aims to reveal the mineralogical characteristics of the carbonate and pelitic rocks in the Lower Triassic Çı̆̆lı Group in the Uludere-Uzungeçit (Şırnak) region from Southeast Anatolian Autochthone (SEAA). Çı̆gll Group is represented by Yoncall Formation (dolomite-siltstone-shale with limestone intercalation), Uludere Formation (shale/shale with carbonate-clayey limestone intercalated with dolomite) and Uzungeçit Formation (limestone with chert nodule-dolomitic limestone-shale) from bottom to top. In order of abundances of minerals obtained by XRD investigations as follows; Yoncall Formation contains carbonate (calcite, dolomite), feldspar, phyllosilicate (illite, chlorite) and goethite minerals, and Uludere Formation is made up of carbonate (calcite, dolomite), quartz, feldspar, phyllosilicate (illite, chlorite, mixed-layered chlorite-vermiculite/C-V, and very minor amount of kaolinite in only a sample) and hematite minerals. Uzungeçit Formation has carbonate (dolomite, calcite), silica (quartz, opalCT, moganite), phyllosilicate (chlorite, illite), and feldspar and hematite minerals. On the basis of illit Kübler Index values; Yoncal Formation reflects the degrees of anchizone; as for Uludere and Uzungeçit formations, they have the degrees of anchizone-high diagenesis, respectively. Similarly, Chlorite Arkai Index $\left(A I,{ }^{\circ} 2 \theta\right)$ values indicate the grades of anchizone-diagenesis. Illites exhibit $2 M_{1}$ ve $2 M_{1}+1 M+$ $1 M_{d}$ polytypes and the values of $b$ unit-cell distances show a composition close to ideal muscovite and low pressure conditions.

The rocks of the Çiğll Group offer differences in terms of rare occurrence of kaolinite, appearance of moganite and $C-V$ and the dominance of dolomite and hematite in most levels, and diagenesis/ metamorphism grades are also high, when compared with the equivalent units in the Diyarbakur-Hazro area. Lower Triassic series regionally seem to have a deeper depositional environment, and have relatively higher maturation because of the volcanic feeding and tectonic burial in the Diyarbaktr-Şirnak direction from west to east.

Key Words: Arabian Plate, XRD, Phyllosilicate, b unit-cell distance, Crystallinity

\section{GİRIŞ}

Arap Levhası'nın Türkiye'de Güneydoğu Anadolu Kuşağı olarak bilinen kesimi; BitlisPütürge Kristalin Karmaşı̆̆ı ve PrekambriyenTersiyer yaşlı otokton sedimanter kayaçlar ile temsil edilen Güneydoğu Anadolu Otoktonu (GDAO) olmak üzere iki tektonik birlikten oluşmaktadır (Göncüoğlu ve diğ., 1997). GDAO Arap Platformu'nun Türkiye sınırları içerisindeki en kuzey kesimini temsil etmekte olup; Alt Triyas yaşlı Çığlı Grubu'na ait kayaçlar bu alanda en yaygın yüzeylemelere sahiptir (Kozak ve diğ., 1977). Çı̆̆lı Grubu kayaçlarının GD Anadolu bölgesindeki eşdeğerleri eşdeğerleri yanal olarak doğudan batıya doğru Hakkari-Çukurca, ŞırnakUludere, Diyarbakır-Hazro ve Antakya-Kırıkhan (Amanos Dağları) yörelerinde gözlenmektedir. Çığlı Grubu Diyarbakır-Hazro yöresinde daha sınırlı yüzlekler sunmakta, Amanoslarda çok daha sınırlı bir yayılıma sahip olduğundan Cudi Grubu içinde değerlendirilmiştir (Bozkaya ve Yalçın, 2013).

Çığlı Grubu kayaçları Diyarbakır-Hazro antiklinali güney kanadında ve Hakkari-Çukurca dolaylarında Paleozoyik yaşılı Gomaniibrik Formasyonu üzerinde uyumsuz, buna karşıı Orta Triyas-Alt Kretase yaşlı Cudi Grubu'na ait Çanaklı Formasyonu ile uyumlu sınır ilişkisi sunmaktadır 
(Tuna, 1973; Perinçek, 1987; Yılmaz, 1982; Günay, 1998). Diyarbakır-Hazro antiklinali güney kanadında ise Çı̆̆lı Grubu'nun üzerinde Mardin
Grubu uyumsuzlukla yer almaktadır (Yılmaz, 1982).

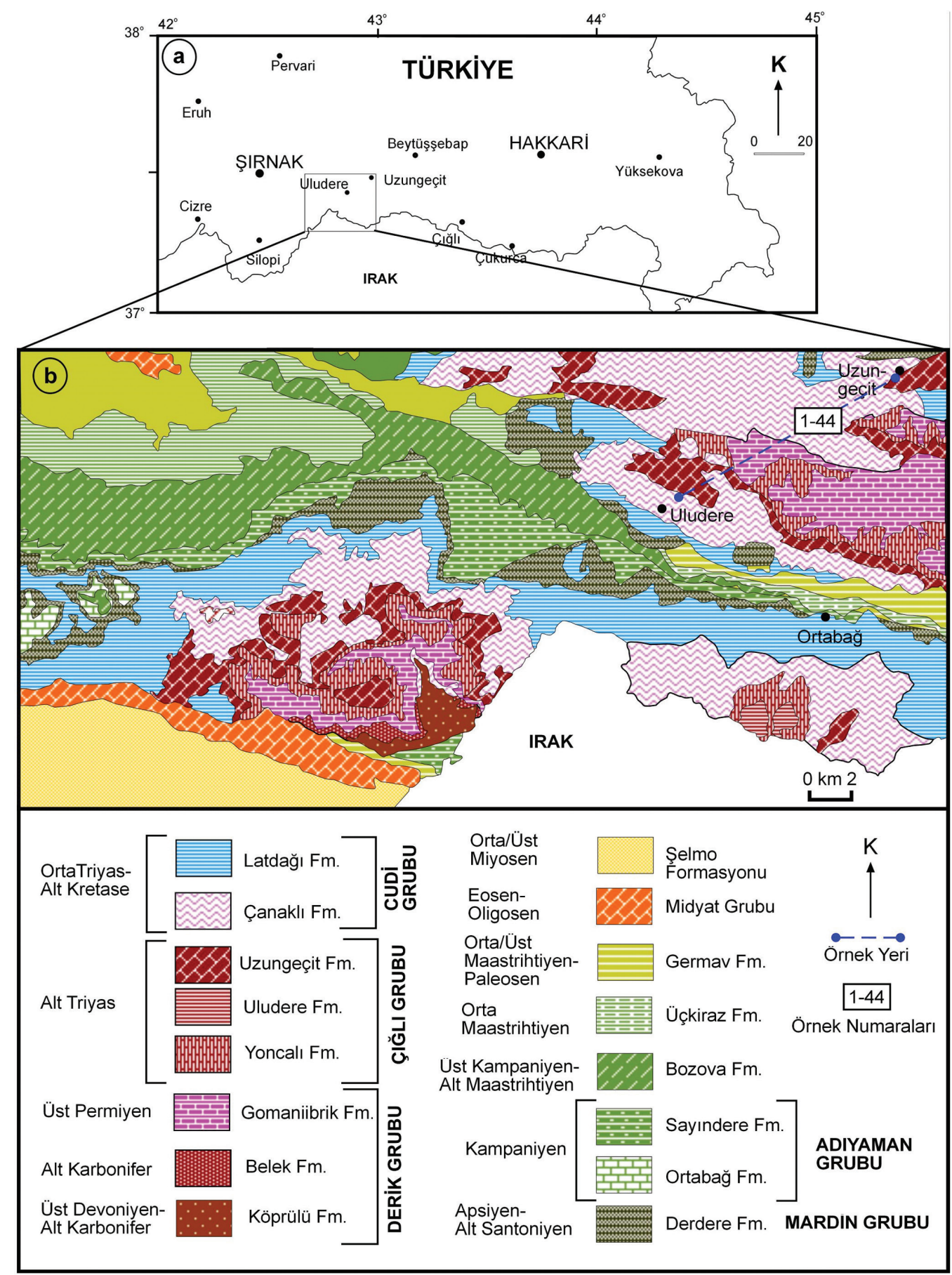

Şekil 1. a) Uludere bölgesinin yer bulduru haritası, b) 1:100.000 ölçekli N49 paftası jeoloji haritası (MTA, 2002).

Figure 1. a) Location map of the Uludere region, b) Geology map of the 1:100.000 scaled N49 sheet (MTA, 2002). 
GDAO'nun (Bozkaya ve Yalçın, 2013; Bozkaya ve diğ., 2009, 2011; Tetiker ve diğ., 2015) ve özellikle Torid Kuşağı'nın (Çelik ve diğ.. 1991; Bozkaya ve Yalçın 2000, 2004a, 2004b, 2005, 2010, 2013; Bozkaya ve diğ., 2002) PaleozoyikMesozoyik yaşlı birimlerinde diyajenetik/ metamorfik tarihçenin aydınlatıldığı birçok ayrıntılı çalışma gerçekleştirilmiştir. Bunları tamamlayıcı nitelikte olmak üzere, bu çalışmada GDAO'nun Uludere-Uzungeçit (Şırnak) bölgesinde yüzeyleyen Çı̆ğlı Grubu'na ait karbonat ve pelitik kayaçların mineralojik özellikleri ortaya konularak, Diyarbakır-Hazro yöresindeki eşdeğerleri ile karşılaştırılması ve sonuçta yanal olarak istiflere ait havzaların provenans, mineral birliktelikleri, diyajenetik/metamorfik evrimlerinin belirlenmesi amaçlanmıştır.

MTA (2002) tarafindan oluşturan jeoloji haritası ve bölgedeki kayaçların stratigrafik dağılımına göre (Şekil 1); Alt Triyas yaşlı Çığlı Grubu birimleri alttan üste doğru Yoncal1, Uludere ve Uzungeçit formasyonlarından oluşmaktadır (Perinçek, 1978; 1980 ve 1990). Yoncalı Formasyonu'nun gel/git düzlüğü-sı ğ deniz ortamında çökeldiği belirtilmiştir (Perinçek ve diğ. 1991). Uludere Formasyonu altta Yoncalı ve üstte ise Uzungeçit formasyonları ile yanal ve düşey geçişli olup (Açıkbaş, 1978; Perinçek, 1980); karasal-geçiş-sığ deniz (Açıkbaş, 1978; Perinçek ve diğ., 1991) ortamında çökeltilmiştir. Altındaki Uludere Formasyonu ile uyumlu ve düşey geçişli olan Uzungeçit Formasyonu sı ̆ deniz-gel/git düzlüğü ortamını (Açıkbaş, 1978; Perinçek ve diğ. 1991) temsil etmektedir. Cudi Grubu birimler (Çanaklı ve Latdağı formasyonları) Çığlı Grubu birimlerini uyumlu olarak üzerlemektedir.

\section{MATERYAL VE YÖNTEM}

1:100.000 ölçekli N49 paftasında yer alan Alt Triyas yaşlı Çı̆̆lı Grubu pelitik-karbonatlı kayaçlardan Uludere-Uzungeçit arasında yapılan arazi çalışmasında noktasal ve ölçülü kesitler (başlangıç $37^{\circ} 29^{\prime} \mathrm{K}, 4^{\circ} 59^{\prime} \mathrm{D}$; bitiş 37²6' $\mathrm{K}, 42^{\circ} 52^{\prime}$ D) boyunca toplam 44 adet örnek alınmıştır. Örnekler üzerinde sırasıyla optik (OM) ve taramalı elektron mikroskobu (SEM), X-1şınları difraksiyonu (XRD)-tüm kayaç (TK) ve kil fraksiyonu (KF) incelemeleri yapılmıştır. OM incelemeleri alttan aydinlatmalı binoküler polarizan mikroskopta, XRD incelemeleri Rigaku Miniflex-2 marka cihazda Batman Üniversitesi Jeoloji Mühendisliği Bölümü Laboratuvarları'nda, SEM incelemeleri ise Türkiye Petrolleri Anonim Ortaklığı Araştırma Merkezi’nde (Ankara) gerçekleştirilmiştir.

OM incelemeleri hazırlanan incekesitlerde NIKON ve LEICA marka binoküler alttan aydinlatmalı polarizan mikroskopta yapılmıştır. $\mathrm{Bu}$ yöntem ile dokusal özellikler, bileşenler, bozuşma (alterasyon) ve bozunma (yüzeysel) ürünleri tanımlanarak kayaçların adlandırılmalarının yanı sıra minerallerin kökeni de aydınlatılmaya çalışılmıştır.

XRD çalışmalarında kullanılan örnekler RECSH marka çeneli kırıcıda 5 mm'den küçük taneler halinde ve yine aynı marka $150 \mathrm{ml}$ kapasiteli silikon karbid çanağa ve $70 \mathrm{rpm}$ dönme hızına sahip öğütücüde kayaçların sertlik durumuna göre ortalama 10-20 dk süreyle ögütülüp plastik poşetlerde paketlenmştir. XRD çözümlemeleri Rigaku marka Minifleks-2 model X-1şınları difraktometresinde (Anot $=\mathrm{CuK} \alpha 1.541871$ $\AA$, Filtre $=\mathrm{Ni}$, gerilim $=35 \mathrm{kV}$, akım $=15 \mathrm{~mA}$, gonyometre hızı $=1$ veya $2 \%$ dak., kağıthızı $=2 \mathrm{~cm} /$ dak., zaman sabiti $=1 \mathrm{sn}$, yarıklar $=1^{\circ} 0.15 \mathrm{~mm}$ $1^{\circ} 0.30 \mathrm{~mm}$, kağıt aralığ ${ }_{1}=2^{\circ}=5-35^{\circ}$ ve $4-30^{\circ}$ ) yapılmıştır. Birimlerden alınan örneklerin tüm kayaç ve kil boyu bileşenleri $(<2 \mu \mathrm{m})$ tanımlanmış ve yarı nicel yüzdeleri de dış standart yöntemi (Brindley, 1980; Yalçın ve Bozkaya, 2002) 
esas alınarak hesaplanmıştır. Kil minerallerinin tanımlanması (001) bazal yansımalarına göre yapılmış olup; zenginleştirme işlemi kimyasal çözme (kil-dışı fraksiyonun uzaklaştırılması), santrifüjleme (Hettich marka Rotina 380 model 5000 devir/dk hiza ve 200 cc kapasiteli polietilen kode) - dekantasyon/dinlendirme - y1kama süspansiyonlama - sedimantasyon - sifonlama şişeleme gibi klasik işlemlerden oluşmaktadır. Kil fraksiyonu difraktogramları normal-N (havada kurutulmuş), glikolleme-EG $\left(60{ }^{\circ} \mathrm{C}\right.$ de 16 saat desikatörde etilen glikol buharında şişirme) ve firınlama-F ( $490{ }^{\circ} \mathrm{C}$ de 4 saat firında 1sitma) işlemlerinden geçirilerek elde edilmiştir.

Kil fraksiyonundan itibaren illit "kristalinite" ölçümü için 10-Å illit pikinin yarı yüksekliğindeki genişliği $\left(\Delta^{\circ} 2 \Theta\right)$ (Kübler indeksi - KI: Kübler, 1968; Guggenheim ve diğ., 2002) kullanılmıştır. Batman Üniversitesi’nde ölçülen KI değerleri CIS standartlarına (Warr ve Rice, 1994) göre kalibre edilmiştir $\left(\mathrm{IC}_{\mathrm{CIS}}=1.344 \mathrm{xIC}_{\mathrm{BU}}+0.002\right.$, $\left.\mathrm{r}^{2}=0.98\right)$. Ankizonun üst ve alt sinırları CIS standartları için 0.25 ve $0.42\left(\Delta^{\circ} 2 \theta\right)$ (Warr ve Rice, 1994) olarak önerilmekle birlikte, Warr ve Ferreiro Mählmann'ın (2015) CIS verilerine ilişkin yeniden değerlendirmeleri doğrultusunda 0.32 ve $0.52\left(\Delta^{\circ} 2 \Theta\right)$ olarak alınmıştır.

Klorit "kristalinite" ölçümlerinde 7-Å klorit pikinin yarı yüksekliğindeki genişliği $\left(\Delta^{\circ} 2 \Theta\right.$; Arkai İndeksi - AI : Arkai, 1991; Guggenheim ve diğ., 2002) kullanılmıştır. Batman Üniversitesi'nde ölçülen AI değerleri CIS standartlarına (Warr ve Rice, 1994) göre ölçülen değerlere dönüştürülmüştür $\quad\left(\mathrm{AI}_{\mathrm{CIS}}=0.701 \mathrm{xAI}_{\mathrm{BU}}+0.102\right.$, $\left.\mathrm{r}^{2}=0.93\right)$. AI için diyajenez-ankizon ve ankizonepizon sinırları sirasiyla 0.33 ve $0.26\left(\Delta^{\circ} 2 \Theta\right)$ olarak önerilmiştir (Arkai, 1991; Arkai ve diğ., 1995; Arkai ve Ghabrial, 1997).
Saf ve/veya safa yakın illit politipleri; XRD yönlendirilmemiş toz çekimlere $(2 \Theta=16$ $36^{\circ}$ ) ait ayırtman pikler (Bailey, 1988) kullanılarak tanımlanmıştır. İllit politip oranları (\%) ise karakteristik pik alanlarının oranlarından itibaren önerilen eşitlikler (Grathoff ve Moore, 1996) yardımıyla hesaplanmaştır.

\section{LİTOLOJİ}

Çığlı Grubu'na ait birimlerin (Yoncalı, Uludere ve Uzungeçit formasyonları) litolojik özellikleri aşağıda sunulmuştur:

Yoncalı Formasyonu silttaş1, şeyl, kireçtaşı ve dolomit ile temsil edilmektedir. Dolomit türü kayaçlar sarı renkli olup; ince-orta tabakalıdır (Şekil 2a). Birim içerisinde sarı-kırmızı-gri renkli karbonatlı silttaşı ve şeyl seviyeleri ardalanma sunmaktadır (Şekil 2b). Birimde kumlu ve/veya siltli kireçtaşı arakatkıları da gözlenmektedir.

Uludere Formasyonu kireçtaşı arakatkıları içeren karbonatlı (kalsit ve/veya dolomit) ve yer yer kumlu kırıntılı kayaç (şeyl ve silttaşı) ardalanmasından oluşmaktadır. Şeyl ve silttaşları sarı, yeşi1, gri, kırmızı ve siyah renkli olup; yaygın olarak midye kabuğu kırılmaları göstermektedir. İnce taneli killi-kırıntılı kayaçlar birbirlerine sıklıkla geçiş göstermektedir. Sarı renkli, killi ve/veya kumlu kireçtaşları sert çıkıntılar halinde bulunmaktadır (Şekil 2c). Birimde yer yer belirgin kıvrımlanmalar da gözlenmektedir (Şekil 2d).

Uzungeçit Formasyonu çört yumrulu kumlu kireçtaşı, dolomit, karbonatlı silttaşı ve şeyl ile temsil edilmektedir. Kireçtaşı seviyeleri sar1gri renkli ve ince tabakalı olup (Şekil 2e); yer yer gri renkli silttaşı ve şeyl ile ara tabakalanmalıdır. Birimin alt seviyelerinde dolomitler sarı renkli ve kalın tabakalı görünüm sunmaktadır (Şekil 2f). 

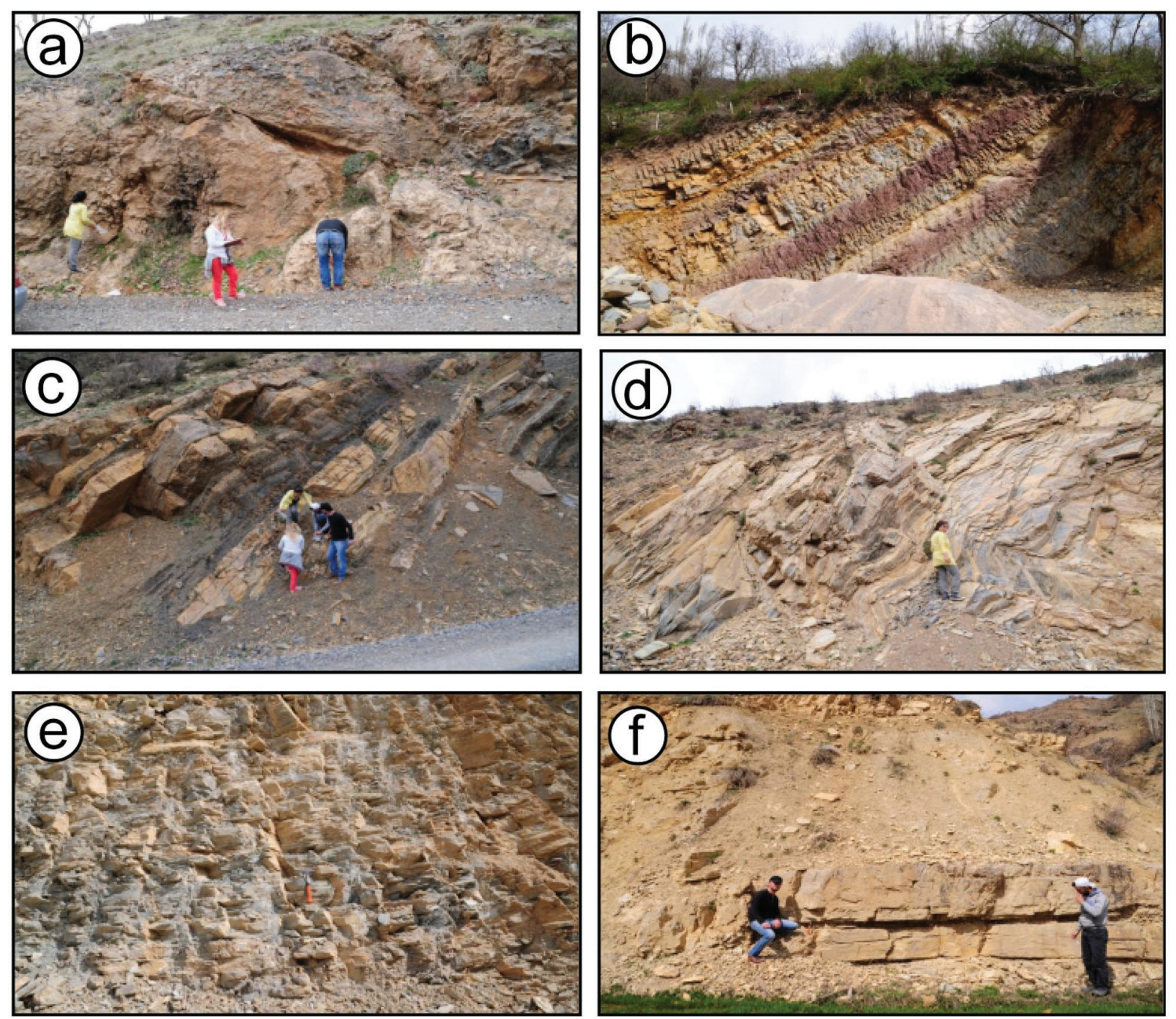

Şekil 2. Çı̆̆lı Grubu kayaçlarının arazi görünümleri, (a) Yoncalı Formasyonu'nun sarı renkli dolomitleri, (b) Yoncalı Formasyonu kırmızı renkli silttaşı ve sarı renkli şeyl ardalanması, c) Uludere Formasyonu'nda sarı renkli kireçtaşı ve siyah renkli şeyl ardalanması, d) Uludere Formasyonu'nda sarı-krem renkli kıvrımlı karbonat-şeyl ardalanması, e) Uzungeçit Formasyonu'nun gri renkli şeyl arakatkılı sarı renkli laminalı kireçtaşları, f) Uzungeçit Formasyonu'nun sarı renkli kalın tabakalı dolomitleri.

Figure 2. Field views of the Çı̆̆ll Group rocks, (a) Yellow colored dolomites from the Yoncall Formation, (b) The alternations of red colored siltstone and yellow colored shale from the Yoncall Formation, c) The alternations of yellow colored limestone and black colored shale from the Uludere Formation, d) The alternations of yellow-cream colored and folded limestone and shale from the Uludere Formation, e) Yellow-gray colored and laminated dolomites with shale interclations from the Uzungeçit Formation, f) Yellow colored and thick bedded dolomites from the Uzungeçit Formation.

\section{PETROGRAFI}

\section{Optik Mikroskop İncelemeleri}

Yoncalı Formasyonu karbonat kayaçlarında dolomit mineralleri iri taneler biçiminde bulunmaktadır (Şekil 3a). Bu kayaçların çatlaklarında kalsit dolguları gözlenmektedir. Şeyller ince taneli olup; laminasyonlar belirgin olarak izlenebilmektedir (Şekil 3b). 

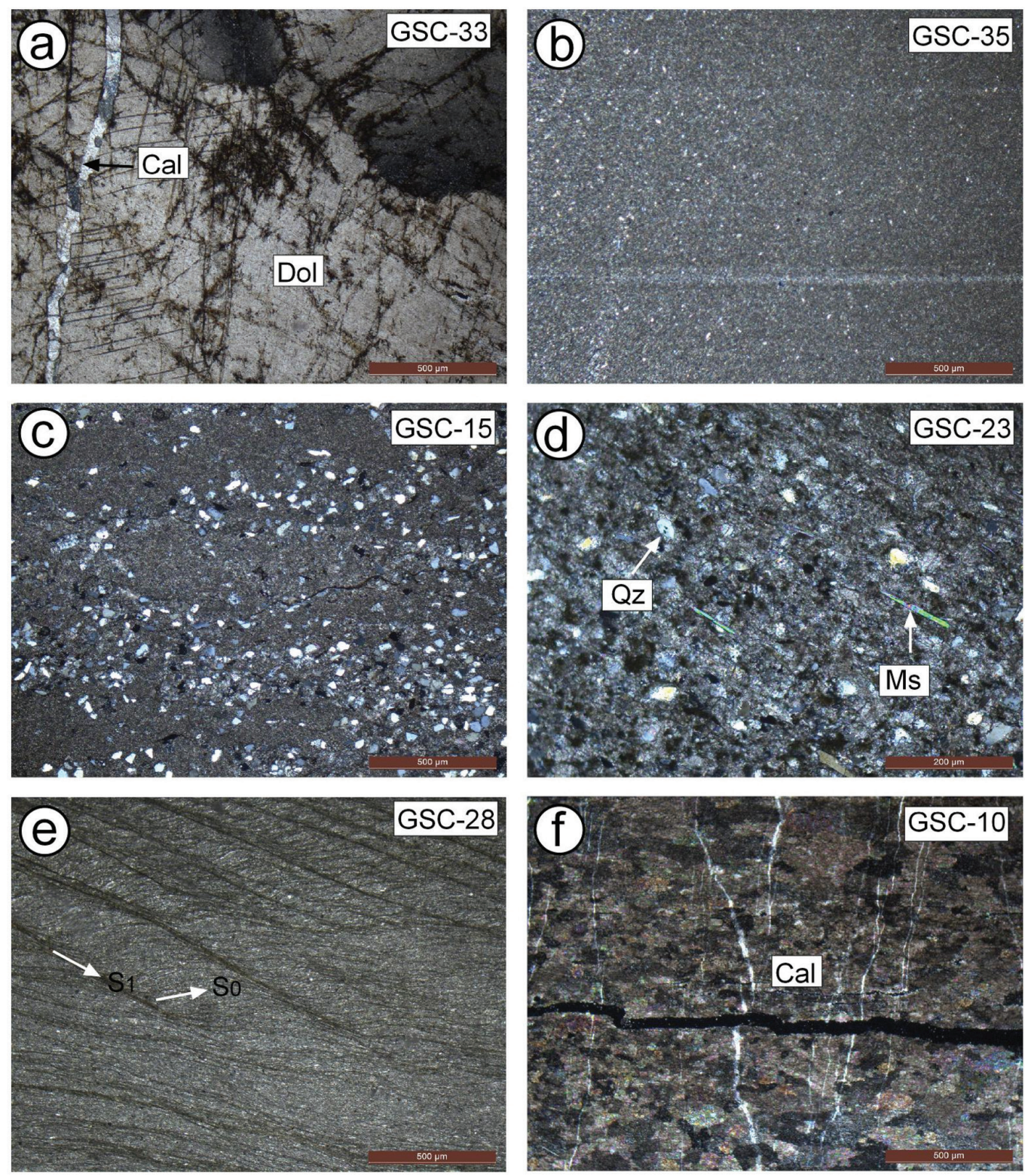

Şekil 3. Çı̆̆lı Grubu kayaçlarının optik mikroskop mikrofotoğrafları (a-d ve f:çift nikol, e:tek nikol; Cal:Kalsit, Dol:Dolomit; Ms:Muskovit, Qz:Kuvars), (a) Yoncalı formasyonu'nda dolomit mineralleri ve çatlaklarda ikincil kalsit oluşumları, (b) Yoncalı Formasyonu'nda ince taneli ve laminalı karbonatlı silttaşı, (c) Uludere Formasyonu'nda kumlu mikrosparit, (d) Uludere Formasyonu'nun karbonatlı silttaşı-şeyl örneğinde yönlenmiş muskovit mineralleri, e) Uludere Formasyonu'nun silttaş1-şeyl örneğinde klivaj dokusu, f) Uzungeçit Formasyonu'nda grift dokulu kireçtaşı.

Figure 3. Optical microscopic microphotograps of the Çı̆̆ll Group rocks (a-d and f:crossed polarized light) crossed polars, e:plane polarized light; Cal:Calcite, Dol:Dolomite, Ms:Muscovite, Qz:Quartz), (a) Dolomite minerals and secondary calcite occurrences in the cracks in the Yoncall Formation, (b) Fine grained and laminated calcareous siltstone in the Yoncall Formation, (c) Sandy microsparite in the Uludere Formation, (d) Oriented muscovite minerals in the calcareous siltstone-shale sample of the Uludere Formasyonu, e) Cleavage texture in the siltstone-shale sample of the Uludere Formation, f) Suture textured limestone in the Uzungeçit Formation. 
Uludere Formasyonu'nun sparitik kireçtaşlarında ortokemi kalsit ve/veya dolomit, litoklastik bileşenleri ise köşeli kuvars taneleri oluşturmaktadır (Şekil 3c). Siltaşı-şeyl örnekleri çoğunlukla karbonat çimentoludur (Şekil 3d). $\mathrm{Bu}$ kayaçlarda silt ve kil tane boyu bileşenlerinin oluşturduğu mikro laminalanma yaygın olup; ince uzun muskovit minerallerinde mikro yönlenmeler ile ince taneli ve köşeli kuvars mineralleri gözlenmektedir. Ayrıca bazı buruşma klivajına sahip pelitik kayaçlarda $S_{0}$ ve $S_{1}$ düzlemleri ayırt edilebilmektedir (Şekil 3e).

Uzungeçit Formasyonu'nun iri taneli (sparitik) kireçtaşları girift/süturlu dokuya sahip olup; bütünüyle kalsit mineralleri ile temsil edilmektedir (Şekil 3f). Bazı kireçtaşları ise ince ve/veya iri taneli bantlar ve kalsit dolgulu çatlaklar ile oldukça ince taneli kuvars ve fillosilikat mineralleri içermektedir.

\section{Taramalı Elektron Mikroskop İncelemeleri}

Yoncalı Formasyonu dolomit örneğinde (GSC33: dolomit + kalsit \pm kil) dolomitler 4-7 $\mu \mathrm{m}$ boyutlarında olup; özşekilli rombohedral yüzeylere sahiptir. Diyajenetik ve/veya otijenik illitler dolomitlerin sinırında ve kısmen de üzerinde gelişmişlerdir (Şekil 4a). Karbonatlı şeyl örneğinde (GSC-35: illit + klorit + kuvars + kalsit + feldispat + dolomit) $5 \mu$ m’yi aşan boyutlarda iri klorit levhaları gözlenmekte olup, prizmatik feldispat tanelerini çevreler biçimde bükülmüşlerdir (Şekil 4b). Diyajenetik illit ve karışık tabakalı klorit-vermikülit (C-V) mineralleri ince tane boyutlu $(<2 \mu \mathrm{m})$ olup, sırasıyla 1şınsallifsel ve levhamsı-saçaksı biçimler sunmaktadır (Şekil 4c).

Uludere Formasyonu pelitik kayaçlarında (GSC-22: klorit + illit $+\mathrm{C}-\mathrm{V}+$ kuvars + kalsit + feldispat + hematit) yar1-özeşekilli, özşekilli levhamsı-bıçaksı kloritler ve ince-taneli saçaksı illitler bulunmaktadır (Şekil 4d). Karışık tabakalı C-V 1şınsal-lifsel biçimli olmalarıyla iri levhamsı illitlerden ayrılmaktadır (Şekil 4e).

Uzungeçit Formasyonu killi kireçtaşı örneğinde (GSC-11: klorit + illit + kalsit + dolomit + kuvars) levhams1 illit/K-mika ve kloritler 1-5 $\mu \mathrm{m}$ arasında değişen boyutlara sahiptir. İllit/Kmika ve kloritler örnekteki yönlenmenin ana bileşenlerini temsil etmekte olup, yönlü levhamsı paketler halinde gözlenmektedir (Şekil 4f). İllitler ince-tane boyutlu $(<2 \mu \mathrm{m})$ yer yer bükülmüş püskülsü-saçaksı biçimleriyle, iri tane boyutlu ( $>2$ $\mu \mathrm{m})$ levhamsı kloritlerden ayırt edilmektedir. 

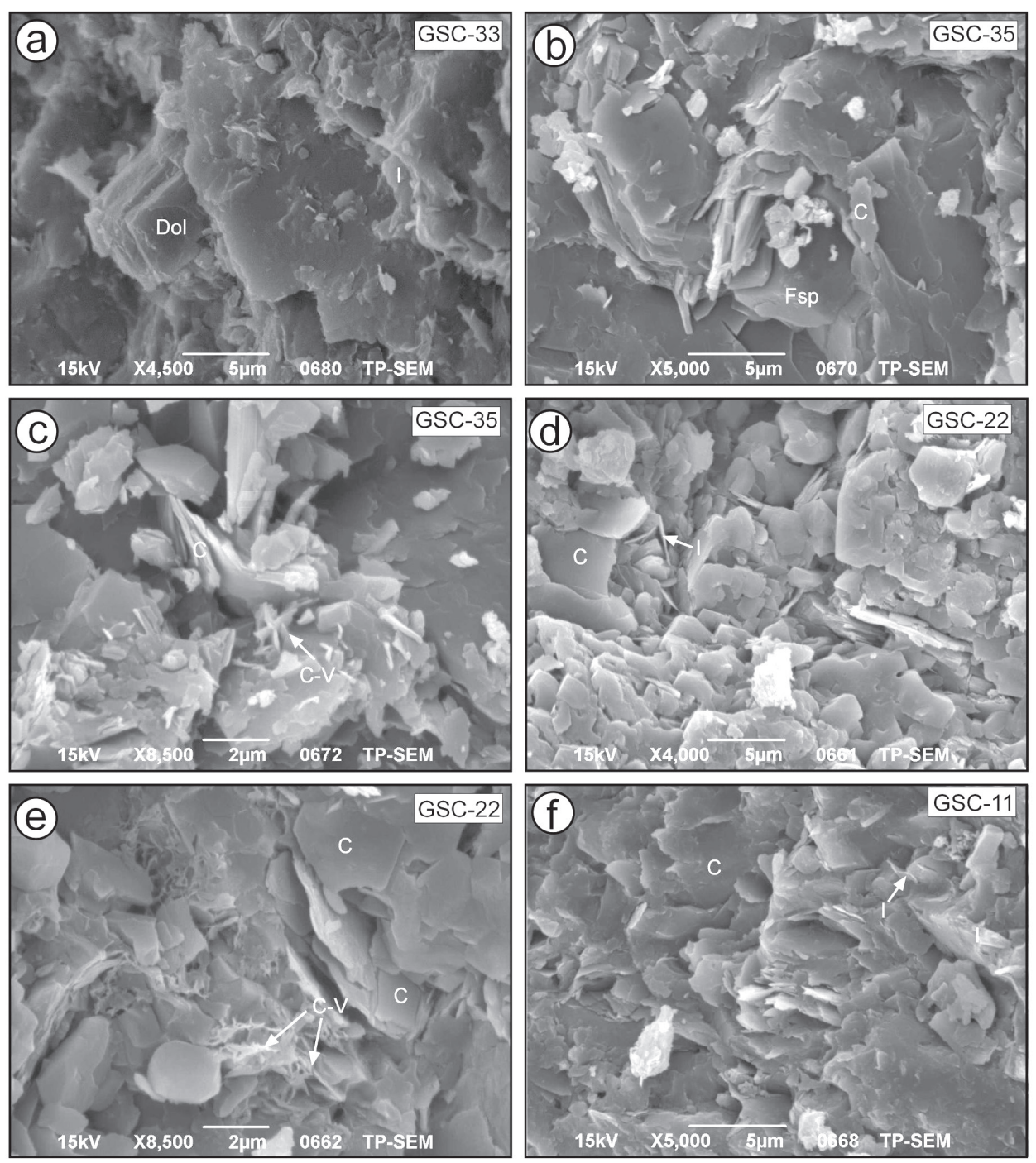

Şekil 4. Çı̆̆lı Grubu kayaçlarının SEM görünümleri (a-c:Yoncalı Formasyonu, d-e:Uludere Formasyonu, f:Uzungeçit Formasyonu; Dol:Dolomit, I:İllit, C:Klorit, C-V:Karışı tabakalı klorit-vermikülit), a) Dolomit örneğinde özşekilli rombohedral dolomit kristalleri ve püskülsü-saçaksı diyajenetik illitler, b) Dolomit örneğinde özşekilli feldispat kristalini çevreleyen sıkı paketlenmiş iri taneli levhamsı kloritler, c) Karbonatlı şeyl örneğinde sıkı paketlenmeli levhamsı kloritler, ışınsal-lifsel karışık tabakalı C-V ve ince levhamsı-saçaksı illitler; d) Şeyl örneğinde yarı-özeşekilli, özşekilli levhamsı-bıçaksı kloritler ve ince taneli saçaksı illitler, e) Şeyl örneğinde iri taneli klorit levhaları arasında 1şınsal-lifsel karışık tabakalı C-V, f) Killi kireçtaşı örneğinde yönlenme gösteren levhamsı klorit plaketleri ve saçaksı illitler.

Figure 4. SEM views of Çı̆̆ll Group rocks (a-c:Yoncall Formation, d-e:Uludere Formation, f:Uzungeçit Formation; Dol:Dolomite, I:Illite, C:Chlorite, C-V:Mixed-layered chlorite-vermiculite), a) Euhedral dolomite crystals and tasseled-fringed diagenetic illites in the dolomite sample, b) Tightly packed and coarse-grained platy chlorites surrounding euhedral feldspar crystal in the dolomite sample, c) Tightly packed and platy chlorites, radial-fibrous mixed-layered $C$-V and fine-grained and fringed illites in the shale with carbonate sample, d) Subhedral to euhedral, platy-bladed chlorites and fine-grained fringed illites in the shale sample, e) Radial-fibrous mixed-layered C-V among coarse-grained chlorite plates in the shale sample, f) Platy and oriented chlorite packets, and fine-grained and fringed illites in the clayey limestone. 


\section{X-IŞINI MINERALOJISİ}

Yoncal1 Formasyonu'nda karbonat (kalsit, dolomit), silis (kuvars, moganit), feldispat, fillosilikat (illit, klorit) ve götit; Uludere Formasyonu'nda karbonat (kalsit, dolomit), kuvars, feldispat, fillosilikat (illit, klorit, karışık tabakalı klorit-vermikülit/C-V, sadece bir örnekte çok eser miktarda kaolinit) ve hematit; Uzungeçit Formasyonu'nda karbonat (dolomit, kalsit), silis (kuvars, opal-CT), fillosilikat (klorit, illit), feldispat ve hematit mineralleri saptanmıştır
(Şekil 5a). Yoncalı Formasyonunda bulunan moganit mineralleri $3.38 \AA$ daki (114) yüzeyine ait pik ile kuvars mineralinin (101) yüzeyinden ayırt edilmiştir (Şekil 5b).

Fillosilikat parajenezleri Yoncalı Formasyonu için illit + klorit; Uludere Formasyonu için illit + klorit, illit + klorit + kaolinit (Şekil 5c) illit + klorit + C-V (Şekil 5d) ve Uzungeçit Formasyonu için illit + klorit birlikteliği (Şekil 5e) ve illit (Şekil 5f) biçiminde dağglım göstermektedir.
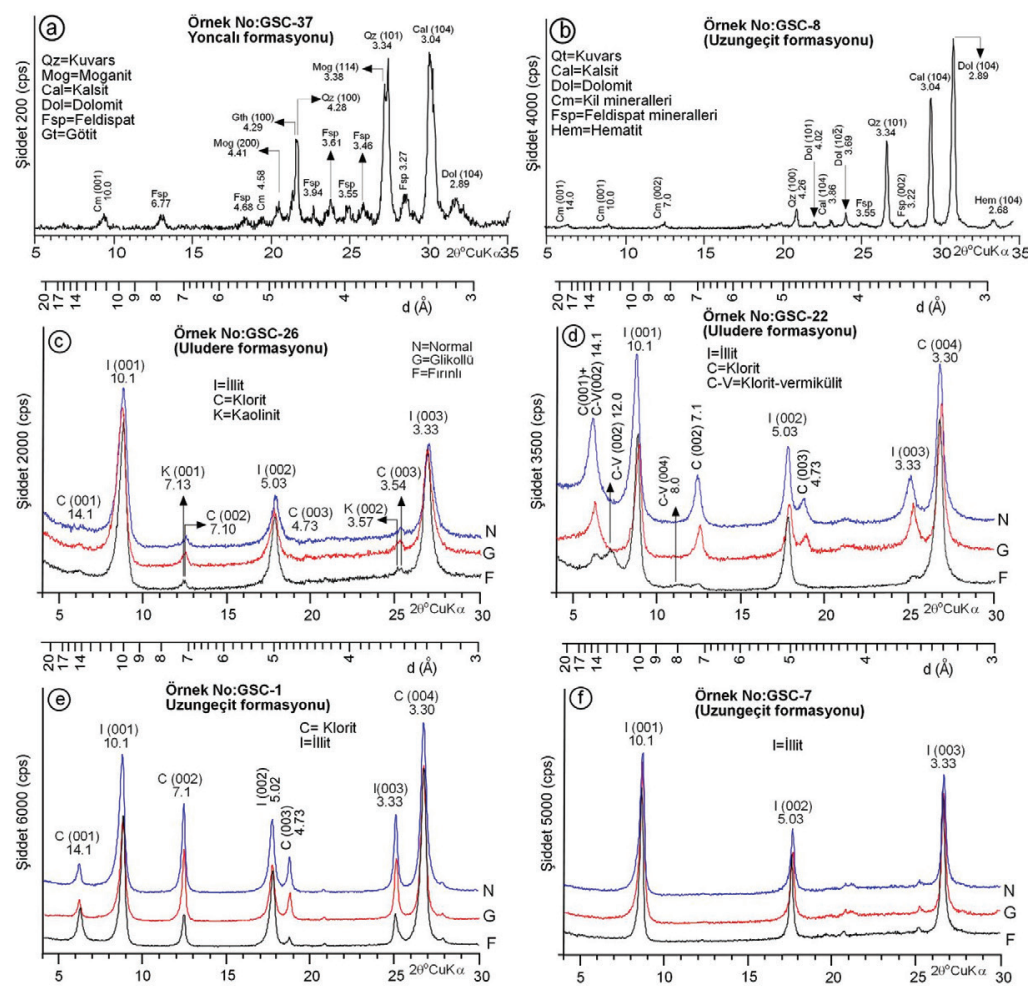

Şekil 5. Çı̆̆lı Grubu kayaçlarının XRD tüm kayaç ve kil fraksiyonu difraktogramları, a) Uzungeçit Formasyonu karbonatlı şeyl örneğinde dolomit ve eşlikçi mineraller, b) Yoncalı Formasyonu siltli şeyl örneğinde moganit ve eşlikçi mineraller, c) Uludere Formasyonu karbonatlı silttaşı-şeyl örneğinde illit + kaolinit + klorit birlikteliği, d) Uludere Formasyonu silttaşı-şeyl örneğinde klorit + illit + karışık tabakalı C-V birlikteliği, e) Uzungeçit Formasyonu killi-kumlu kireçtaşı örneğinde klorit + illit birlikteliği, f) Uzungeçit Formasyonu killi kireçtaş1 örneğinde yaklaşık saf illit minerali.

Figure 5. XRD whole-rock and clay fraction difractograms of Çı̆̆ll Group rocks, a) Dolomit and associated minerals in the sample of shale with carbonate from Uzungeçit Formation, b) Moganite and associated minerals in the sample of silty shale from Yoncall Formation, c) Chlorite + illite assocation in the sample of clayey-sandy limestone from Uzungeçit Formation, d) Illite + kaolinite + chlorite assocation in the sample of siltstone-shale from Uludere Formation, e) Chlorite + illite + mixed-layered C-V assocation in the sample of siltstone-shale from Uludere Formation, f) Nearly pure illit mineral in the sample of clayey limestone from Uzungeçit Formation. 
Uzundere Formasyonu illitleri GSC-7 ve GSC-11 nolu örnekler için sirasıyla $2 M_{1}(\%$ $85)+1 M_{\mathrm{d}}(\% 15)$ ve $2 M_{1}(\% 45)+1 M(\% 10)$ $+1 M_{\mathrm{d}}(\%$ 45) politipleri sergilemektedir (Şekil
6). İllit $b$ birim-hücre mesafeleri 8.952-8.995 $\AA$ (ortalama $8.971 \AA$ ) olup; ideal muskovite yakin bir bileşimi ve düşük basınç fasiyesi koşullarını göstermektedir.

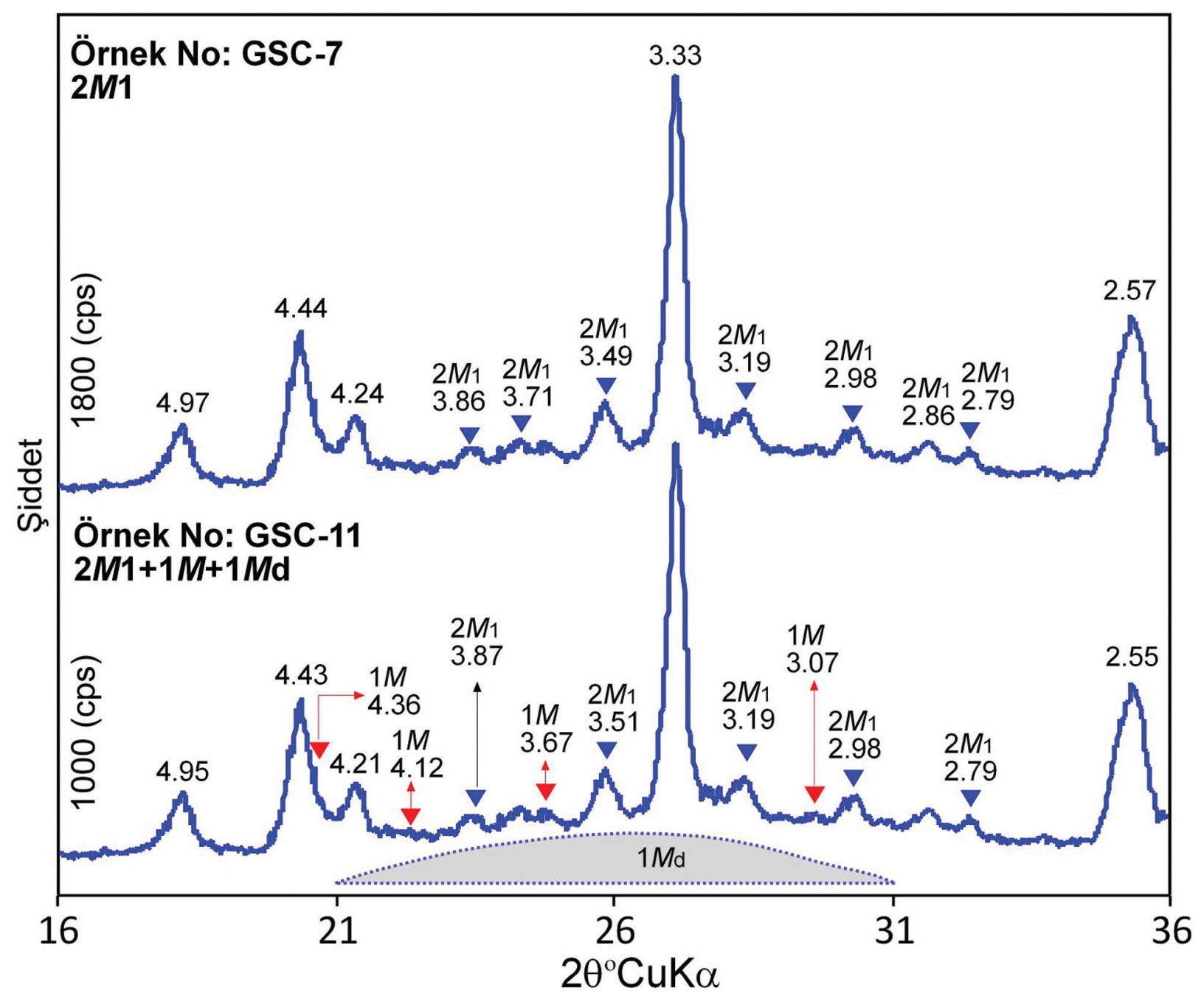

Şekil 6. Uzungeçit Formasyonu'nda $2 M_{1}$ ve $2 M_{1}+1 M+1 M_{\mathrm{d}}$ politiplerine sahip illitlerin yönlendirilmemiş XRD toz difraktogramları.

Figure 6. XRD unoriented powder diffractograms of $2 M_{1}$ and $2 M_{1}+1 M+1 M_{d}$ polytypes from illites in the Uzungeçit Formation. 
İllit minerallerinde Kübler İndeksi: KI (Kübler, 1968; $\Delta^{\circ} 2 \Theta$ ) değerlerine göre; Yoncalı Formasyonu yüksek ankizon (0.32-0.40, ortalama 0.35$)$; Uludere (0.32-0.72, ortalama $0.46)$ ve Uzungeçit $(0.26-0.50$, ortalama 0.37$)$ formasyonları ise ankizon-yüksek diyajenez derecesini yansıtmaktadır (Şekil 7a).

Klorit minerallerine ait Arkai İndeks (AI: $\left.\Delta^{\circ} 2 \Theta\right)$ değerleri (Arkai, 1991; Guggenheim ve diğ., 2002) Yoncalı Formasyonu için 0.28-0.71 (ortalama 0.41), Uludere Formasyonu için 0.260.50 (ortalama 0.37 ) ve Uzungeçit Formasyonu için 0.27-0.42 (ortalama 0.34) arasında değişmektedir. AI ve KI verileri birlikte değerlendirildiğinde, ankizon-diyajenez derecelerine sahip birimler birbirinden ayrılmaktadır (Şekil 7b). Ayrıca, Arkai (1991) tarafından önerilen epizon başlangıç sinırıyla $\left(\mathrm{AI}<0.26 \Delta^{\circ} 2 \theta\right)$ aynı, buna karşın ve ankizon üst sınırına karşılık gelen AI değerinden $\left(\mathrm{AI}=0.33 \Delta^{\circ} 2 \Theta\right)$ farklıdır $\left(\mathrm{AI}=0.49 \Delta^{\circ} 2 \Theta\right)$.

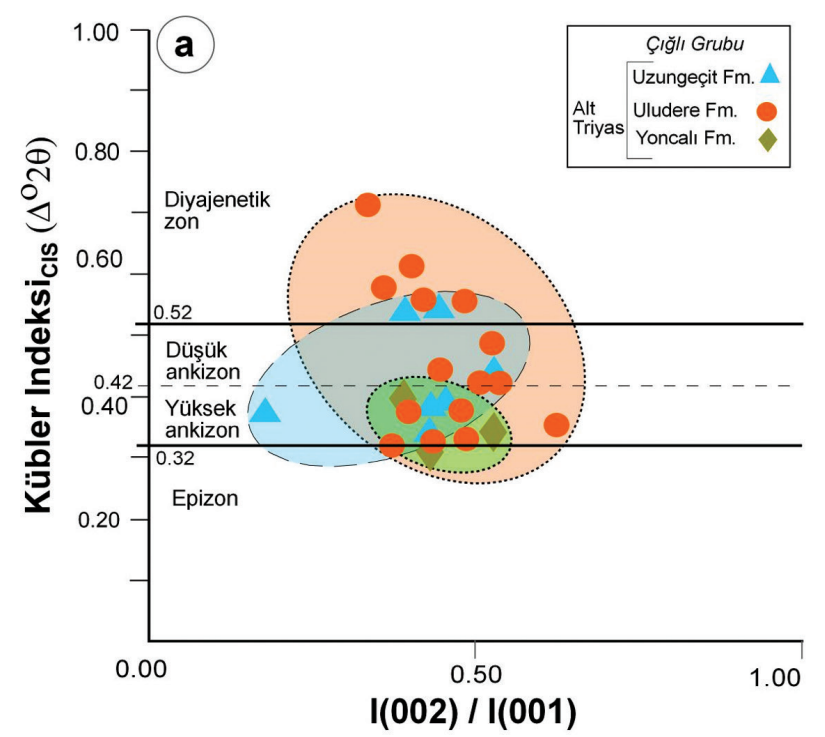

Birimleri oluşturan minerallerin dikey dağılımlarına göre (Şekil 8); Yoncalı Formasyonu için moganit, Uludere Formasyonu için karışık tabakalı C-V ve Uzungeçit Formasyonu için dolomit ve opal-CT tipik ve/veya en bol bulunan minerallerdir.

\section{TARTIŞMA VE SONUÇLAR}

Alt Triyas yaşlı Çı̆glı Grubu birimleri alttan üste doğru artan basınç-sıcaklık ile uyumlu olarak ankizon-diyajenetik zon biçiminde gelişen sedimanter gömülme ile ilişkili ortaya çıkan dokusal ve mineralojik özelliklere sahiptir. Dokusal ve mineralojik izleri özellikle pelitik kayaçlardaki klivaj dokusu, illit/K-mika ve klorit yönlenmeleri ile illit-K-mika ve klorit-C-V dönüşümleri oluşturmaktadır. Diğer taraftan; illit + klorit ve yer yer eşlik eden karışık tabakalı $\mathrm{C}-\mathrm{V}$ birlikteliğinin baskınlığı ve kaolinitin ender bulunması ve smektitin bulunmayışı artan gömülmeyle birlikte meydana gelen mineralojik değişim/dönüşümlere işaret etmektedir.

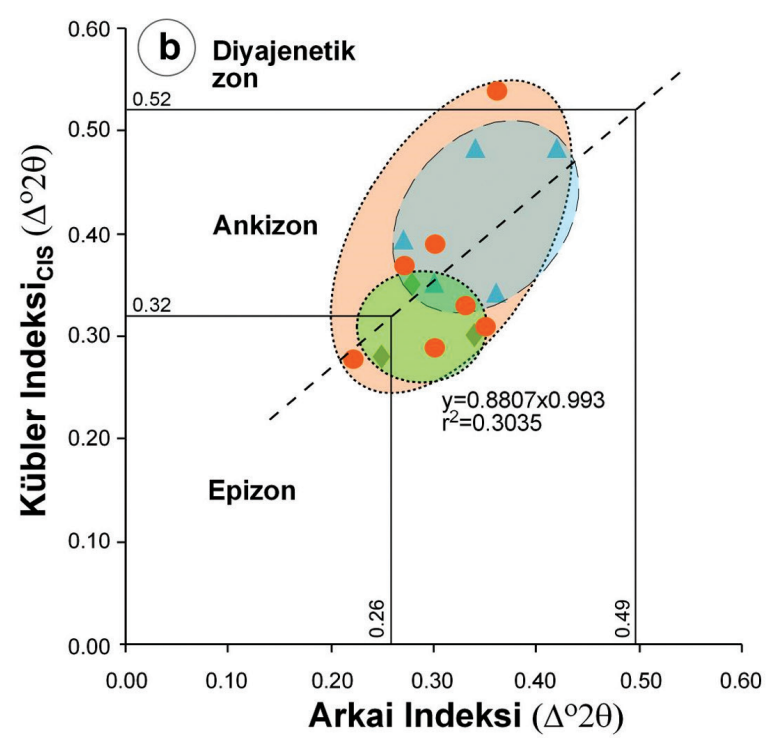

Şekil 7. Çı̆̆lı Grubu kayaçlarının diyajenetik/metamorfik dereceleri, a) K-mikalarda KI ve I(002)/(001) pik şiddeti oranlarına göre dağılımları, b) K-mikalarda KI ve AI değerleri arasındaki ilişki.

Figure 7. The diagenetic/metamorphic grades of the Çı̆̆ll Group rocks, a) The distributions of KI and I(002)/(001) peak intensity ratios in the K-micas, b) The relationships between KI and AI values in the K-micas. 


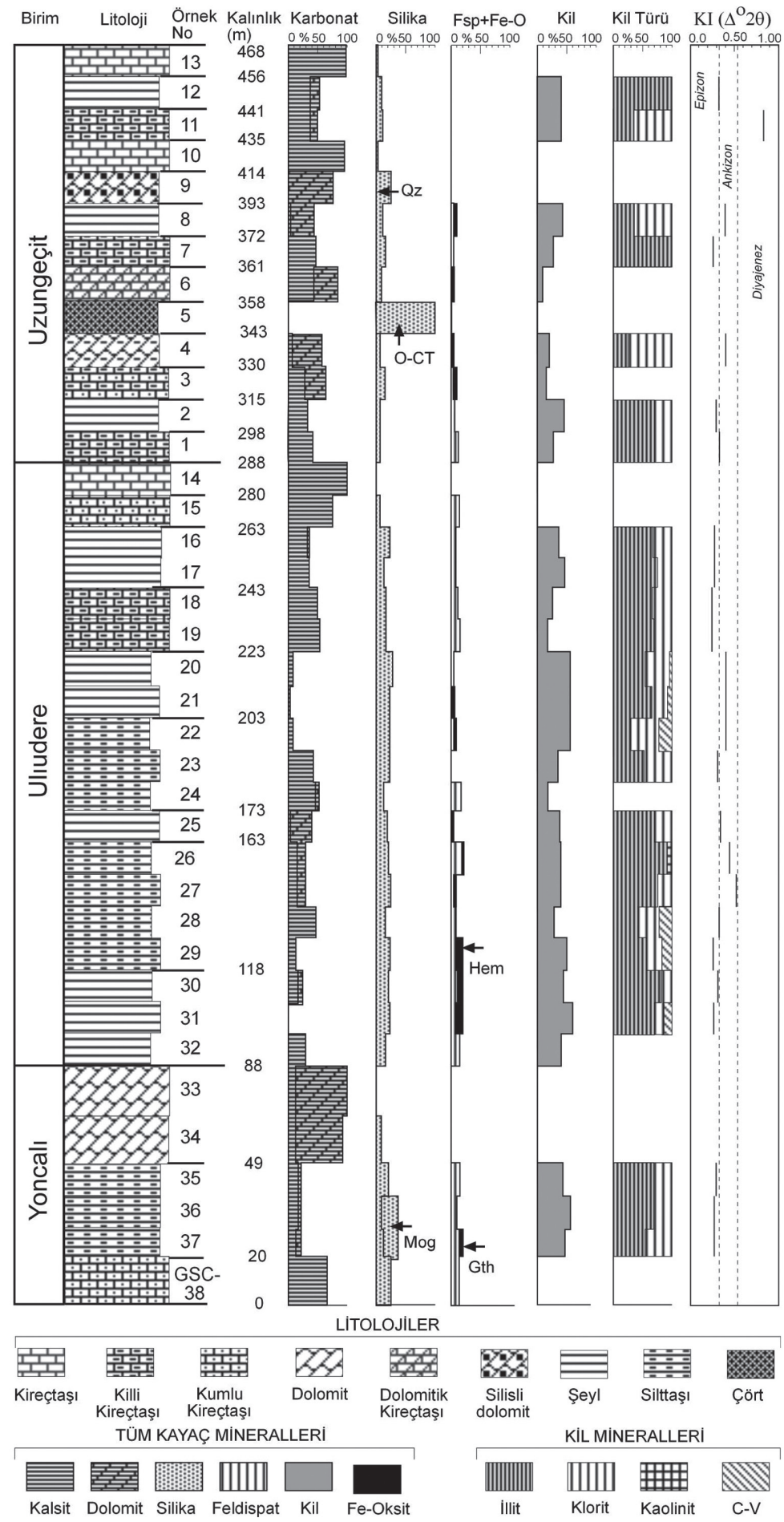

Şekil 8. Çı̆̆lı Grubu’nda saptanan minerallerin dikey dağılımları (Qz:Kuvars, Mog:Moganit, O-CT:Opal-CT, Fsp:Feldispat, Hem:Hematit, Gth:Götit).

Figure 8. The vertical distributions of minerals determined in the Çı̆̆ll Group(Qz:Quartz, Mog:Moganite, O-CT:Opal-CT, Fsp:Feldspar, Hem:Hematite, Gth:Goethite). 
Kloritlerin yarı-özşekilli levhamsıprizmatik biçimli iri kristaller halinde gözlenmeleri, mevcut diyajenetik koşullardan daha yüksek diyajenez/metamorfizma koşullarını (detritik köken) yansıtmakla birlikte, illitlerin saçaksı, karışık tabakalı C-V minerallerinin ışınsallifsel biçimli olmaları, bunların detritik kökenden ziyade, sedimanter koşullarla ilişkili (diyajenetik/ otijenik) olduklarını göstermektedir. Diğer bir ifadeyle, İllit/K-mika ve klorit minerallerinin levhamsı paketler halinde yönlenmeleri; ayrıca bu minerallerin kristal-kimyasal verileri (KI ve politipi) ileri diyajenez/çok düşük dereceli metamorfizma koşullarını yansıtmaktadır.

Şırnak-Uludere-Uzungeçit ve DiyarbakırHazro yörelerinde yüzeyleyen Çığlı Grubu'nun eşdeğer birimlerine göre (Bozkaya ve diğ., 2011) mineralojik bileşim farklılıkları sergilemektedir (Çizelge 1). İnceleme alanında yer alan formasyonlar özellikle dolomit ve çörtlerin baskınlığı bakımından Hazro bölgesindekilerden (Bozkaya ve diğ., 2011) farklıdır. Tüm kayaç mineralojisi bakımından değerlendirildiğinde; Hazro bölgesinde jips ve glokonit; incelenen alanda ise $\mathrm{Fe}$-oksit/hidroksit (hematit ve götit) ve opal-CT'nin baskınlığının yanı sıra; moganit minerali de ortaya çıkmaktadır. GDAO birimlerinde moganit minerali ilk defa Mardin (Derik-Kızıltepe) yöresindeki Alt Paleozoyik ve Mesozoyik yaşlı birimlerde saptanmıştır (Tetiker ve diğ., 2012). Bir silika minerali olarak monoklinik sistemde kristalleşen moganitin deneysel ve gözlemsel verilerle diyajenetik kökene sahip olduğu ifade edilmektedir (Flörke ve diğ., 1976, 1984; Dunn ve diğ., 1985; Weintraub 1993; Heaney 1995; Heaney ve Post 1992, 2001; Gíslason ve diğ., 1997). İnceleme alanında silika minerallerinin bolluğu (kuvars, opal-CT ve moganit); bu mineralin oluşumunda volkanojenik beslenme ve/veya biyokimyasal süreçlerin egemen olduğunu düşündürmektedir. Ayrıca bu mineralin Türkiye'de GDAO, bölgesel anlamda ise Arap Levhası kayaçları için ayırt edici olduğu ileri sürülebilir gözükmektedir. Fillosilikat mineralojisi açısından değerlendirildiğinde; Hazro bölgesinden glokonit, karışık tabakalı illit-smektit (I-S) ve kısmen kaolinitin yaygınlığına karşın; inceleme alanında kaolinit mineralleri ender olarak bulunmakta; buna karşın karışık tabakalı C-V mineralleri ortaya çıkmaktadır.

İllit politiplerinden $1 M$ ve $1 M_{\mathrm{d}}$ diyajenetik (Merriman ve Peacor 1999; Grathoff ve diğ., 2001; Bozkaya ve Yalçın, 2010; Bozkaya ve diğ., 2012); $1 M$ ise magmatik (volkanik) mika (Merriman ve Roberts, 1985; Lopez-Munguira ve diğ., 1998; Bozkaya ve diğ., 2002) kökene; $2 M_{1}$ detritik ve/veya yüksek diyajenetik-çok düşük dereceli metamorfik (Örneğin; Frey, 1987; Merriman ve Peacor 1999; Grathoff ve diğ., 2001; Grathoff ve Moore, 2002; Bozkaya ve Yalçın, 2010 ve 2013; Bozkaya ve diğ., 2012) kökene işaret etmektedir. Diğer bir ifadeyle illit politipleri olasılı volkanik beslenmenin yanı sıra, artan diyajenez/metamorfizma derecesi ile de sentezlenmiş gözükmektedir.

Fillosilikatların kristal-kimyasal verilerine göre; Şırnak-Uludere-Uzungeçit yöresindeki Alt Triyas yaşlı birimlerin Diyarbakır-Hazro yöresindeki eşdeğer birimlere göre (Bozkaya ve diğ., 2011) daha yüksek diyajenez/metamorfizma derecesine sahip olduğu anlaşılmaktadır. Bu durum istiflerin paleocoğrafik dağılımlarının ve provenansının yanı sıra maruz kaldığı tektonizmayla da ilişkilidir. Diğer bir ifadeyle, Alt Triyas serileri daha derin bir çökelme ortamına ve yayılımına, volkanik beslenim ile daha yüksek sedimanter ve tektonik gömülmeye sahip gözükmektedir. 
Çizelge 1. Çı̆̆lı Grubu kayaçlarının Şırnak-Uludere ve Diyarbakır-Hazro (Bozkaya ve diğ., 2011) bölgelerindeki mineralojik özelliklerinin karşılaştırılması (Cal:Kalsit, Dol:Dolomit, Qz:Kuvars, O-CT:Opal-CT, Fsp:Feldispat, PS:Fillosilikat; Mog:Moganit, Gth:Götit, Gp:Jips, G:Glokonit, I:İllit, I-S:Karışık tabakalı illit-smektit, K:Kaolinit, C:Klorit, C-V:Karışık tabakalı klorit-vermikülit, CS:Kristalit boyutu).

Table 1. The comparison of mineralogical properties of Çı̆gll Group rocks in the Şlrnak-Uludere and Diyarbakır-Hazro (Bozkaya et al., 2011) regions (Cal:Calcite, Dol:Dolomite, Qz:Quartz, O-CT:OpalCT, Fsp:Feldspar, PS:Phyllosilicate; Mog:Moganite, Gth:Goethite, Gp:Gypsum, G:Glauconite, I:Illite, I-S:Mixed-layered illite-smectite, K:Kaolinite, C:Chlorite, C-V: Mixed-layered chlorite-vermiculite, CS:Crystallite size).

\begin{tabular}{|c|c|c|c|c|c|c|c|c|}
\hline Bölge & Birim & Litoloji & Mineral & PS & $\mathrm{KI}\left(\Delta^{\circ} 2 \Theta\right)$ & $\mathrm{d}_{060}(\AA)$ & Politipi & $\mathrm{CS}(\mathrm{nm})$ \\
\hline $\begin{array}{l}\text { Diyarbakır- } \\
\text { Hazro }\end{array}$ & Çığlı & $\begin{array}{c}\text { Şeyl } \\
\text { Kireçtaş1 } \\
\text { Dolomit } \\
\text { Marn } \\
\text { Kumtaş1 }\end{array}$ & $\begin{array}{l}\mathrm{Cal}+\mathrm{Dol}+\mathrm{PS}+\mathrm{Qz}+\mathrm{Fsp}+ \\
\mathrm{Gth}+\mathrm{Gp}\end{array}$ & $\begin{array}{l}\mathrm{I}+\mathrm{G}+ \\
\mathrm{I}-\mathrm{S}+\mathrm{K}\end{array}$ & $\begin{array}{l}0.81-1.14 \\
\text { (ort.1.00) }\end{array}$ & $\begin{array}{c}1.5033- \\
1.5053 \\
\text { (ort.1.5041) }\end{array}$ & $\begin{array}{c}1 M \\
2 M_{1}+1 M_{\mathrm{d}}\end{array}$ & $\begin{array}{l}7-10 \\
\text { (ort.9) }\end{array}$ \\
\hline \multirow{3}{*}{$\begin{array}{l}\text { Şırnak- } \\
\text { Uludere }\end{array}$} & Uzungeçit & $\begin{array}{l}\text { Kireçtaş1 } \\
\text { Şeyl }\end{array}$ & $\begin{array}{l}\mathrm{Cal}+\mathrm{Dol}+\mathrm{Qz}+\mathrm{O}-\mathrm{CT}+\mathrm{Fsp} \\
+\mathrm{PS}+\mathrm{Hem}\end{array}$ & $\mathrm{C}+\mathrm{I}$ & $\begin{array}{l}0.31-0.48 \\
\text { (ort. } 0.38 \text { ) }\end{array}$ & \multirow{3}{*}{$\begin{array}{c}1.4921- \\
1.4991 \\
\text { (ort.1.4953) }\end{array}$} & $\begin{array}{c}2 M_{1}+1 M_{\mathrm{d}} \\
2 M_{1}+1 M+1 M_{\mathrm{d}}\end{array}$ & $\begin{array}{c}12-34 \\
\text { (ort.22) }\end{array}$ \\
\hline & Uludere & $\begin{array}{l}\text { Silttaş1 } \\
\text { Şeyl }\end{array}$ & $\begin{array}{l}\mathrm{Cal}+\mathrm{Dol}+\mathrm{Qz}+\mathrm{Fsp}+\mathrm{PS}+ \\
\mathrm{Hem}\end{array}$ & $\mathrm{I}+\mathrm{C}+\mathrm{C}-\mathrm{V} \pm \mathrm{K}$ & $\begin{array}{l}0.28-0.63 \\
\text { (ort. } 0.40 \text { ) }\end{array}$ & & & $\begin{array}{c}17-29 \\
\text { (ort.22) }\end{array}$ \\
\hline & Yoncalı & $\begin{array}{l}\text { Dolomit } \\
\text { Silttaş1 } \\
\text { Seyl }\end{array}$ & $\begin{array}{l}\mathrm{Cal}+\mathrm{Dol}+\mathrm{Qz}+\mathrm{Mog}+\mathrm{Fsp}+ \\
\mathrm{PS}+\mathrm{Gth}\end{array}$ & $\mathrm{I}+\mathrm{C}$ & $\begin{array}{l}0.28-0.35 \\
\text { (ort. } 0.31 \text { ) }\end{array}$ & & & $\begin{array}{c}24-29 \\
\text { (ort.28) }\end{array}$ \\
\hline
\end{tabular}

\section{KATKI BELIRTME}

Yazarlar, arazi çalışmalarındaki destekleri için Batman Üniversitesi Jeoloji Mühendisliği Bölümü stajyer öğrencileri Özge ERENG, M.Şirin BASUTCU, M.Salih BULUT ve Sinan BEKİROĞLU'na; bilimsel hakemler olarak katkılarından dolayı Necati KARAKAYA (Selçuk Üniversitesi) ve S. Zehra KARAKAŞ'a (Ankara Üniversitesi) teşekkür ederler.

\section{EXTENDED SUMMARY}

Çı̆̆lı Group of Lower Triassic age has common and typical outcroppings in the UludereUzungeçit (Şırnak) region of the Southeast Anatolian Autochthone (SEAA) forming the northern extension of the Arabian Platform. It is represented by Yoncalı Formation (dolomitesiltstone-shale with limestone intercalation), Uludere Formation (shale/shale with carbonateclayey limestone intercalated with dolomite) and Uzungeçit Formation (limestone with chert nodule-dolomitic limestone-shale) from bottom to top. This study aims to reveal the mineralogical characteristics of the carbonate and pelitic rocks in the Çı̆glı Group. In this scope, optical and scanning electron microscopies, and also X-rays diffraction (whole-rock, clay fraction, $b$ dimension and polytypes) methods were performed on the samples. In order of abundances of minerals obtained by XRD investigations as follows; Yoncal1 Formation contains carbonate (calcite, dolomite), feldspar, phyllosilicate (illite, chlorite) and goethite minerals, and Uludere Formation is made up of carbonate (calcite, dolomite), quartz, feldspar, phyllosilicate (illite, chlorite, mixed-layered chlorite-vermiculite/C-V, and very minor amount of kaolinite in only a sample) and hematite minerals. Uzungeçit Formtion has carbonate (dolomite, calcite), silica (quartz, opalCT, moganite), phyllosilicate (chlorite, illite), and feldspar and hematite minerals. On the basis of illit Kübler Index-KI $\left(\Delta^{\circ} 2 \theta\right)$ values; Yoncalı Formation reflects the degrees of anchizone (0.32- 
0.40, mean 0.35); as for Uludere and Uzungeçit formations, they have the degrees of anchizonehigh diagenesis (0.32-0.72, mean 0.46 and 0.350.82 , mean 0.48), respectively. Similarly, Chlorite Arkai Index (AI, $\left.\Delta^{\circ} 2 \Theta\right)$ values indicate the grades of anchizone-diagenesis: Yoncal1 Formation 0.280.71 (mean 0.41), Uludere Formation 0.26-0.50 (mean 0.37) and Uzungeçit Formation 0.29-0.40 (mean 0.34). Illites exhibit $2 M_{1}$ ve $2 M_{1}+1 M+1 M_{\mathrm{d}}$ polytypes and the values of $b$ unit-cell distances (from 8.952 to $8.995 \AA$ with an average $8.971 \AA$ ) show a composition close to ideal muscovite and low pressure conditions. The rocks of the Çı̆glı Group offer differences in terms of rare occurrence of kaolinite, appearance of moganite and $\mathrm{C}-\mathrm{V}$ and the dominance of dolomite and hematite in most levels, and diagenesis/metamorphism grades are also high, when compared with the equivalent units in the Diyarbakır-Hazro area of SEAA. This event is related with tectonism as well as paleogeographic setting and provenance of sequences. In other words, Lower Triassic series seem to have a deeper depositional environment, volcanic feeding and tectonic burial from west to east.

\section{DEĞİNILLEN BELGELER}

Açıkbaş, D., 1978. Çukurca-Köprülü-Yığınlı (Hakkari ili) alanının jeolojisi ve hidrokarbon olanakları. TPAO Arama Grubu Rapor No: 2303, 67 s.

Arkai, P., 1991. Chlorite crystallinity: an empirical approach and correlation with illite crystallinity, coal rank and mineral facies as exemplified by Palaeozoic and Mesozoic rocks of northeast Hungary. Journal of Metamorphic Geology, 9, 723-734.

Arkai, P., Ghabrial, D.S. , 1997. Chlorite crstallinity as an indicator of metamorphic grade of lowtemperature meta-igneous rocks: a case study form the Bükk Mountains, Northeast Hungary. Clay Minerals, 32, 205-222.
Arkai, P., Sassi, F.P., Sassi, R., 1995. Simultaneous measurements of chlorite and illite crystallinity: A more reliable geothermometric tool for monitoring low- to very low-grade metamorphisms in metapelites: A case study from the Southern Alps (NE Italy). European Journal of Mineralogy, 7, 1115-1128.

Bailey, S.W., 1988. X-ray diffraction identification of the polytypes of mica, serpentine, and chlorite. Clays and Clay Minerals, 36, 193-213.

Bozkaya, Ö., Yalçın, H., 2000. Very low-grade metamorphism of Upper Paleozoic-Lower Mesozoic sedimentary rocks related to sedimentary burial and thrusting in Central Taurus Belt, Konya, Turkey. International Geology Review, 42, 353367.

Bozkaya, Ö., Yalçın, H., 2004a. New mineralogical data and implications for the tectono-metamorphic evolution of the Alanya Nappes, Central Tauride Belt, Turkey. International Geology Review, 46, 347-365.

Bozkaya, Ö., Yalçın, H., 2004b. Diagenetic to lowgrade metamorphic evolution of clay mineral assemblages in Palaeozoic to early Mesozoic rocks of the Eastern Taurides, Turkey. Clay Minerals, 39, 481-500.

Bozkaya, Ö., Yalçın, H., 2005. Diagenesis and very low-grade metamorphism of the Antalya Unit: mineralogical evidence of Triassic rifting, AlanyaGazipaşa, Central Taurus Belt, Turkey. Journal of Asian Earth Sciences, 25, 109-119.

Bozkaya, Ö., Yalçın, H., 2010. Geochemistry of mixedlayer illite-smectites from an extensional basin, Antalya Unit, Southwestern Turkey. Clays and Clay Minerals, 58, 644-666.

Bozkaya, Ö., Yalçın, H., 2013. Geochemical monitoring of clays for diagenetic evolution of the PaleozoicLower Mesozoic sequence in the northern Arabian plate: Hazro and Amanos regions, Southeastern Turkey. Journal of African Earth Sciences, 86, 1024.

Bozkaya, Ö., Yalçın, H., Göncüoğlu, M.C., 2002. Mineralogic and organic responses to the stratigraphic irregularities: An example from the Lower Paleozoic very low-grade metamorphic units of the Eastern Taurus Autochthon, 
Turkey. Schweizerische Mineralogische und Petrographische Mitteilungen, 82, 355-373.

Bozkaya, Ö., Yalçın, H., Kozlu, H., 2009. Amanoslar bölgesi Paleozoyik kayaçlarının mineralojisi. H.Ü.Yerbilimleri, 30, 11-44.

Bozkaya Ö., Yalçın H., Kozlu, H., 2011. Clay mineralogy of the Paleozoic-Lower Mesozoic sedimentary sequence from the northern part of the Arabian Platform, Hazro (Diyarbakır), Southeast Anatolia. Geologica Carpathica, 62, 489-500.

Bozkaya, Ö., Yalçın, H., Göncüoğlu, M.C., 2012. Diagenetic and very low-grade metamorphic characteristics of the Paleozoic series of the Istanbul Terrane (NW Turkey). Swiss Journal of Geosciences, 105, 2, 183-205.

Brindley, G.W., 1980. Quantitative x-ray mineral analysis of clays. In: Crystal Structures of Clay Minerals and Their X-ray Identification (G.W. Brindley, G.Brown, eds.), Mineralogical Society, London, 411-438.

Çelik, M., Karakaya, N., Turan, A., 1991. Erken Paleozoyik yaşlı killerin mineraloji ve metamorfizma özellikleri: Konya güney ve güneybatısı. V. Ulusal Kil Sempozyumu, Anadolu Üniversitesi, Eskişehir, 16-20 Eylül, Bildiriler Kitabı (Ed. M.Zor), 62-73

Dunn, P.J., Fleischer, M., Shigley, J.E., Zilczer, J.A., 1985. New mineral names. American Mineralogist, $70,871-881$

Flörke, O.W., Flörke, U., Giese, U., 1984. Moganite, a new microcrystalline silica-mineral. Neues Jahrbuch für Mineralogie-Abhandlungen, 149, 325-336.

Flörke, O.W., Jones, J.B., Schmincke, H.U., 1976. A new microcrystalline silica from Gran Canaria. Zeitschrift für Kristallographie, 143, 156-165

Frey, M., 1987. Very low-grade metamorphism of clastic sedimentary rocks. In: Low Temperature Metamorphism (M. Frey, ed.), Glasgow, Blackie and Son, 9-58.

Gíslason, S.R., Heaney, P.J., Oelkers, E.H., Schott, J., 1997. Kinetic and thermodynamic properties of moganite, a novel silica polymorph. Geochimica et Cosmochimica Acta, 61, 1193-1204.
Göncüoğlu, M.C., Dirik, K., Kozlu, H., 1997. General characteristics of pre-Alpine and Alpine Terranes in Turkey: Explanatory notes to the terrane map of Turkey. Annales Geologique de Pays Hellenique, 37, 515-536.

Grathoff, G. H., Moore, D. M., 1996. Illite polytype quantification using Wildfire $\bigcirc$ calculated X-ray diffraction patterns. Clays and Clay Minerals, 44, 835-842.

Grathoff, G.H., Moore, D.M., 2002. Characterization of the Waukesha Illite: a mixed-polytype illite in the Clay Minerals Society repository. American Mineralogist, 87, 1557-1563.

Grathoff, G. H., Moore, D. M., Hay, R. L., Wemmer, K., 2001. Origin of illite in the lower Paleozoic of the Illinois basin: Evidence for brine migrations. Geology Society of America Bulletin, 113, 10921104.

Guggenheim, S., Bain, D.C., Bergaya, F., Brigatty, M.F., Drits, A., Eberl, D.D., Formoso, M.L.L., Galan, E., Merriman, R.J., Peacor, D.R.., Stanjek, H., Watanabe, T., 2002. Report of the AIPEA nomenclature committee for 2001: Order, disorder and crystallinity in phyllosilicates and the use of the "Crystallinity Index". Clay Minerals, 37, 389393.

Günay, Y., 1998. Güneydoğu Anadolu'nun JeolojisiStratigrafisi. Türkiye Petrolleri Anonim Ortaklı̆̆ Arama Grubu Başkanlığı, Rapor No: 3939, 27 s.

Heaney, P.J., 1995. Moganite as an indicator for vanished evaporites: A testament reborn? Journal of Sedimentary Research, A65, 633-638.

Heaney, P.J., Post, J.E., 1992. The widespread distribution of a novel silica polymorph in microcrystalline quartz varieties. Science, 255, 441-443.

Heaney, P.J, Post, J.E., 2001. Evidence for an I2/a to Imab phase transition in the silica polymorph moganite at $\sim 570 \mathrm{~K}$. American Mineralogist, 86, 1358-1366.

Kozak, S., Pasin, C., Mancarc1, M., Tosunkara, A. 1977. Uzungeçit ölçülmüş stratigrafi kesiti. Türkiye Petrolleri Anonim Ortaklı̆̆ı, Arama Grubu Başkanlı̆̆ı, Rapor No: 8622. 
Kübler, B., 1968. Evaluation quantitative du métamorphisme par la cristallinité de l'illite. Bulletin-Centre de Recherches Pau-SNPA, 2, 385397.

López-Munguira, A., Nieto, F., 2000. Transmission Electron Microscopy study of very low-grade metamorphic rocks in Cambrian sandstones and shales. Ossa-Morena Zone, South-West Spain. Clays and Clay Minerals, 48, 213-223.

Merriman R.J., Peacor, D.R. 1999. Very low-grade metapelites: Mineralogy, microfabrics and measuring reaction progress. In: Low Grade Metamorphism (M. Frey, D. Robinson, eds.), Blackwell Sciences Ltd., Oxford, 10-60.

Merriman, R.J., Roberts, B., 1985. A survey of white mica crystallinity and polytypes in pelitic rocks of Snowdonia and Llyn, North Wales. Mineralogical Magazine 49, 305-319.

MTA, 2002. 1:100 000 Ölçekli N49 Cizre Paftası Jeoloji Haritası. MTA Genel Müdürlüğü, Ankara.

Perinçek, D., 1978. Çelikhan-Sincik-Koçali (Adiyaman ili) alanının jeolojik incelemesi ve petrol olanaklarının araştırılması. İstanbul Üniversitesi Fen Fakültesi Tatbiki Jeoloji Kürsüsü, Doktora Tezi, Türkiye Petrolleri Anonim Ortaklığı, Arama Grubu Başkanlığı, Rapor No: 1250, 212 s.

Perinçek, D., 1980. IX. Bölge Hakkari, Yüksekova, Çukurca, Beytüşşebap, Uludere, Pervari dolayının jeolojisi. Türkiye Petrolleri Anonim Ortaklığı, Arama Grubu Başkanlığı, Rapor No: 1481, 80 s.

Perinçek, D., 1987. IX. Bölge Hakkari, Yüksekova, Çukurca, Beytüşşebap, Uludere, Pervari dolayının jeolojisi. Türkiye Petrolleri Anonim Ortaklığı, Arama Grubu Başkanlığı, Rapor No: 1481, 80 s.

Perinçek, D., 1990. Hakkari ili ve dolayının stratigrafisi, GDA Türkiye: Türkiye Petrol Jeologları Derneği Bülteni, 2, 21-68.

Perinçek, D., Duran, O., Bozdoğan, N., Çoruh, T., 1991. Stratigraphy and paleogeographical evolution of the autochthonous sedimentary rocks in the SE Turkey. Ozan Sungurlu Symposium, Ankara, Proceedings, 274-305.

Tetiker, S., Yalçın, H., Bozkaya, Ö., 2012. Güneydoğu Anadolu otoktonu Mardin (Derik-K1zıltepe) yöresinde Prekambriyen-Erken Paleozoyik yaşlı kayaçların mineralojik ve petrografik özellikleri. Türkiye Petrol Jeologları Derneği Bülteni, 24, 2347.

Tetiker, S., Yalçın, H., Bozkaya, Ö., 2015. Evidence of the diagenetic history of sediment composition in Precambrian-Early Paleozoic rocks: A study from the Southeast Anatolian Autochthon, Mardin (Derik-Kizıltepe), Turkey. Arabian Journal of Geoscience, 5, 11261-11278.

Tuna, D., 1973. VI. Bölge litostratigrafi birimleri adlamasının açıklayıcı raporu. Türkiye Petrolleri Anonim Ortaklı̆̆ı, Arama Grubu Başkanlığı, Rapor No: 813, $131 \mathrm{~s}$.

Warr, L.N., Farreiro Mählmann, R., 2015. Recommendations for Kübler Index standardization. Clay Minerals, 50, 283-286.

Warr, L.N., Rice, A.H.N., 1994. Interlabratory standartization and calibration of clay mineral crystallinity and crystallite size data. Journal of Metamorphic Geology, 12, 141-152.

Weintraub, B., 1993. Within common quartz, a common new mineral. National Geographic Magazine, 184,5 .

Yalçın, H., Bozkaya, Ö., 2002. Hekimhan (Malatya) çevresindeki Üst Kretase yaşlı volkaniklerin alterasyon mineralojisi ve jeokimyası: Deniz suyu-kayaç etkileşimine bir örnek. Cumhuriyet Üniversitesi Mühendislik Fakültesi Dergisi Seri A-Yerbilimleri, 19, 81-98.

Yılmaz, E., 1982. Hazro (Diyarbakır) güneybatı yöresinin jeolojisi. İstanbul Teknik Üniversitesi, Jeoloji Kürsüsü, Diploma Çalışması, 53 s.

\begin{tabular}{ll}
\hline Makale Geliş Tarihi & $:$ 20 Temmuz 2016 \\
Kabul Tarihi & $:$ 16 Ağustos 2016 \\
& $:$ 20 July 2016 \\
Received & $:$ 16 August 2016
\end{tabular}

